\title{
Autophagy supports survival and phototransduction protein levels in rod photoreceptors
}

\author{
Z Zhou' ${ }^{1}$, TA Doggett ${ }^{1}$, A Sene ${ }^{1}$, RS Apte ${ }^{1}$ and TA Ferguson ${ }^{*, 1}$
}

Damage and loss of the postmitotic photoreceptors is a leading cause of blindness in many diseases of the eye. Although the mechanisms of photoreceptor death have been extensively studied, few studies have addressed mechanisms that help sustain these non-replicating neurons for the life of an organism. Autophagy is an intracellular pathway where cytoplasmic constituents are delivered to the lysosomal pathway for degradation. It is not only a major pathway activated in response to cellular stress, but is also important for cytoplasmic turnover and to supply the structural and energy needs of cells. We examined the importance of autophagy in photoreceptors by deleting the essential autophagy gene Atg5 specifically in rods. Loss of autophagy led to progressive degeneration of rod photoreceptors beginning at 8 weeks of age such that by 44 weeks few rods remained. Cone photoreceptor numbers were only slightly diminished following rod degeneration but their function was significantly decreased. Rod cell death was apoptotic but was not dependent on daily light exposure or accelerated by intense light. Although the light-regulated translocation of the phototransduction proteins arrestin and transducin were unaffected in rods lacking autophagy, Atg5-deficient rods accumulated transducin- $\alpha$ as they degenerated suggesting autophagy might regulate the level of this protein. This was confirmed when the light-induced decrease in transducin was abolished in Atg5-deficient rods and the inhibition of autophagy in retinal explants cultures prevented its degradation. These results demonstrate that basal autophagy is essential to the long-term health of rod photoreceptors and a critical process for maintaining optimal levels of the phototransduction protein transducin- $\alpha$. As the lack of autophagy is associated with retinal degeneration and altered phototransduction protein degradation in the absence of harmful gene products, this process may be a viable therapeutic target where rod cell loss is the primary pathologic event.

Cell Death and Differentiation (2015) 22, 488-498; doi:10.1038/cdd.2014.229; published online 9 January 2015

Autophagy is an intracellular pathway where cytoplasmic constituents are delivered to the lysosomes for degradation. Defective autophagy can contribute to the age-dependent accumulation of damaged proteins and organelles leading to altered cellular homeostasis and loss of function. ${ }^{1-5}$ The metabolic roles of autophagy can be classified into two types, basal and induced. In nutrient-rich conditions, autophagy is suppressed but still occurs at low levels (basal autophagy); however, when cells are subjected to stress (starvation, injury, hypoxia), autophagy is activated immediately (induced autophagy). ${ }^{6}$ Induced autophagy maintains the amino acid pool inside cells to adapt to starvation while constitutive autophagy has been shown to function as a cell-repair mechanism that is important for long-lived postmitotic cells. ${ }^{7-11}$ Defects in autophagy have been associated with neurodegenerative diseases, ${ }^{12-15}$ diabetes, ${ }^{16,17}$ lysosomal storage disease ${ }^{18}$ and the loss of vision. ${ }^{19}$ In addition to macroautophagy, microautophagy and chaperone-mediated autophagy (CMA) have been described. Although little is known about microautophagy in mammalian cells, macroautophagy (hereafter autophagy) is a major pathway for bulk degradation of cytoplasmic components. CMA is a more selective pathway for degradation of cytosolic proteins that can compensate for the loss of macroautophagy. 2,20-22

Inherited retinal degenerative diseases such as retinitis pigmentosa or Leber's congenital amaurosis are characterized by premature and progressive death of rod and cone photoreceptor cells. ${ }^{23}$ These diseases are characterized by the loss of night vision due to the death of rods followed by the loss of cones leading to diminished visual acuity and a reduction in the quality of life for patients. Disease is typically associated with the production of harmful gene products that promote pathology by inhibiting critical pathways resulting in cell death. ${ }^{24-26}$ Strategies to prevent photoreceptor death during retinal degenerative disease such as gene replacement therapies or inhibition of cell death pathways have been undertaken with some success; ${ }^{27-29}$ however, effective treatments for these blinding disorders are lacking.

Another strategy that could be used in conjunction with other therapies might be to enhance survival by stimulating autophagy. Augmenting autophagy would increase the supply of nutrients to stressed cells and accelerate removal of damaged proteins thereby prolonging cell survival beyond what would be possible by only preventing cell death. Although canonical $^{22,30-33}$ and noncanonical autophagic mechanisms ${ }^{34}$

${ }^{1}$ Department of Ophthalmology and Visual Sciences, Washington University School of Medicine, St Louis, MO 63110, USA

${ }^{*}$ Corresponding author: TA Ferguson, Department of Ophthalmology and Visual Sciences, Washington University School of Medicine, 660 S. Euclid, Box 8096 , St Louis, MO 63110, USA. Tel: +1 314362 3745; Fax: +1 314747 4238; E-mail: ferguson@ vision.wustl.edu

Abbreviations: L/D, light/dark; Atg5, autophagy-related gene 5; T $\alpha$, rod transducin alpha subunit; Gnat1, guanine nucleotide binding protein alpha transducin 1; Arr, arrestin; CMA, chaperone-mediated autophagy; LC3B, Microtubule-associated protein 1 light chain 3 beta; RPE, retinal pigment epithelium; ONL, outer nuclear layer; OS, outer segments

Received 24.6.14; revised 21.11.14; accepted 26.11.14; Edited by M Piacentini; published online 09.1.15 
have been detected in the eye, our knowledge of basic autophagy functions in this organ is still limited. In order to understand how autophagy maintains retinal homeostasis and function, we undertook studies to examine the consequences of deleting the essential autophagy gene Atg5 in rod photoreceptors.

\section{Results}

Deletion of Atg5 in rod photoreceptors. As mice deficient in Atg5 or Atg7 die soon after birth, ${ }^{35,36}$ we generated the Atg $5^{\Delta \text { Rod }}$ mouse strain in which basal autophagy was deleted specifically in rod photoreceptors (see Methods for details). Western blot analysis of the neurosensory retina revealed that Atg5/12 expression was reduced beginning at 6 weeks of age with further reduction in this complex at 8 and 16 weeks
(Figure 1a). The conversion of microtubule-associated protein 1 light chain 3B (LC3B-I) to its lipidated form (LC3B-II) was almost completely suppressed at these time points suggesting that much of the detectable LC3B processing in the retina takes place in the rods. Importantly, Atg5-deficient retinae accumulated p62/SQSTM1, a hallmark of defective autophagy, ${ }^{37,38}$ further substantiating the loss of basal autophagy in the rods. Quantification of the LC3B-II and p62/SQSTM1 (Figures 1b and $\mathrm{c}$, respectively) by determining their average abundance relative to the actin control in three separate experiments confirmed these findings. Analysis of Lamp2A (Figures 1a and d) and Hsc70 (Figures $1 \mathrm{a}$ and $\mathrm{e}$ ) revealed that these proteins were not increased in the whole retina suggesting that CMA was not elevated at these time points.

Progressive rod degeneration in $A t g 5^{\Delta R o d}$ mice. Photoreceptors are non-replicating, postmitotic cells that must
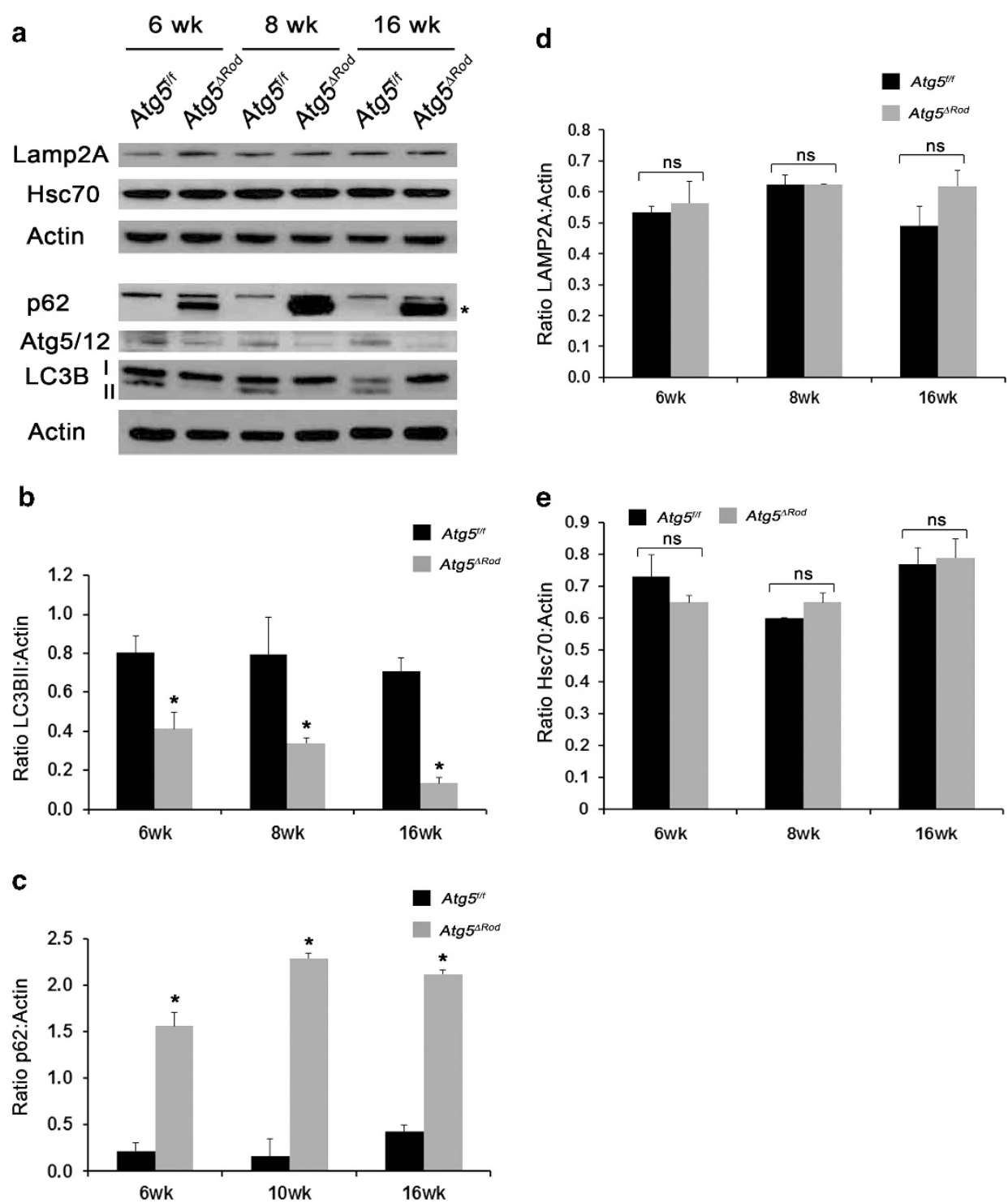

Figure 1 Deletion of Atg5 in rod photoreceptors. (a) Representative western blots of retinae from $A \operatorname{tg} 5^{\Delta R o d}$ and control $\left(\operatorname{Atg} 5^{\mathrm{f} / 4}\right)$ mice examining Atg5/12, p62/SQSTM1 ( $\left.{ }^{*}\right)$, Lamp2A, Hsc70, LC3B-I and LC3B-II. ( b-e) Relative expression levels of specific proteins compared with actin in 6, 8 and 16-week-old Atg $5^{f / f}$ and Atg $5^{\Delta R o d}$ mice averaged from three separate experiments; (b) LC3BII ( $\left.{ }^{*} P<0.05\right)$, (c) p62 ( $\left.{ }^{*} P<0.05\right)$, (d) Lamp2A, (e) Hsc70. ns = not significantly different 
survive the life of an organism without the possibility of renewal suggesting autophagy may be an essential process for cellular repair and energy. ${ }^{7}$ Consequently, we examined the long-term consequences of Atg5 deletion in the Atg $5^{\Delta \text { Rod }}$ mouse strain. Morphometric analysis demonstrated that beginning at 8 weeks of age the density of the outer nuclear layer (ONL) was significantly decreased compared with control. Over the next 36 weeks, ONL thickness steadily declined such that by 44 weeks, $>90 \%$ of the ONL nuclei were depleted in both the inferior and superior regions of the retina (Figure 2a). These observations are represented in the micrographs shown in Figures $2 \mathrm{~b}$ and $\mathrm{c}$ where aging had no effect on the ONL of control mice $\left(\operatorname{Atg}^{f /+} ; \mathrm{Cre}^{+}\right)$but in the Atg $5^{\Delta R o d}$ strain the ONL was gradually reduced to the thickness of a few nuclei (Figure 2c). We also detected increased numbers of terminal deoxynucleotidyl transferasemediated dUTP nick end labeling $\left(\mathrm{TUNEL}^{+}\right)$nuclei in the ONL of $A \operatorname{tg} 5^{\Delta R o d}$ mice (Figures $3 a$ and $b$ ) as well as nuclei with apoptotic morphology (Figure 3c) suggesting that rod photoreceptor death was by apoptosis. We also noted that other layers of the retina such as the inner nuclear layer, ganglion cell layer and retinal pigment epithelium (RPE) were not overtly affected by rod deterioration.

Rod degeneration in $A t g 5^{\Delta R o d}$ mice is not dependent on light exposure. It has been suggested that autophagy is a mechanism by which photoreceptors control the level of opsins in response to changes in lighting levels. ${ }^{39,40}$ Controlling opsin levels is critical to suppressing lightdependent retinal degeneration that could occur following the absorption of too many photons. Thus, one prediction would be that light exposure of the Atg $5^{\Delta R o d}$ mice would promote rod degeneration because of the inability of the rods to regulate rhodopsin levels, and that in the absence of light, degeneration would be inhibited. We tested this hypothesis by comparing rod degeneration in mice maintained on the standard light/dark (L/D) cycle in our animal facility to mice that were maintained in continuous darkness. These results show that whether $A \operatorname{tg} 5^{\Delta R o d}$ mice were maintained in the L/D cycle or dark-adapted similar numbers of ONL nuclei were lost from all regions of the retina (Figure 4a).

Light-induced retinal degeneration has been observed in certain strains of mice and this is dependent on a polymorphism in the RPE65 protein expressed in the RPE. ${ }^{41,42}$ Mice with a leucine at position 450 (Leu-450) (e.g., BALB/c and 129) are susceptible to light stress, whereas mice with a methionine at position 450 (Met-450) (e.g., C57BL/6) are resistant. The Leu450 amino acid results in an accelerated RPE visual cycle and leads to degeneration of the photoreceptors because of the rapid accumulation of toxic visual cycle products in the RPE. In strains with Met-450, the slower visual cycle does not lead to toxic product accumulation or degeneration. The Atg $5^{\Delta R o d}$ mice are on the C57BL/6J background permitting us to test the effect of intense light on Atg5-deficient photoreceptors without the confounding effects of the RPE-visual cycle. First, we exposed the light-stress-susceptible strain 129/SvImJ to 13000 lux white light for $7 \mathrm{~h}$ and observed a significant loss of ONL nuclei in the inferior and superior regions of the retina demonstrating that this light intensity can induce severe retinal damage in a susceptible strain (Figure 4b). We then exposed
$A \operatorname{tg} 5^{\Delta R o d}$ to light under the same conditions and observed that rod degeneration was not accelerated (Figure $4 b$ ) as mice exposed to intense light had a similar ONL thickness to Atg $5^{\Delta R o d}$ mice maintained in the normal L/D cycle. Thus, without the influence of the RPE visual cycle, autophagy in rod photoreceptors is not a protective mechanism under conditions of intense bright light.

Cones are preserved structurally but not functionally in $\boldsymbol{A t g} 5^{\Delta R o d}$ mice. In many retinal degenerative diseases, rod cell loss is often accompanied by degeneration of the cone photoreceptors. ${ }^{30}$ In $A t g 5^{\Delta R o d}$ mice, rods are decreased by $>90 \%$ by 38 weeks of age; however, when cone numbers were assessed at this time, only $10 \%$ of the cones were lost (Figure 5a, Supplementary Figure 1). Examination of cone morphology by co-staining with PNA (green) and specific antibodies to M-opsin (red) and S-opsin (blue) revealed that the remaining cones had significantly shorter outer segments (OSs) (Figure 5b, arrowheads). This was confirmed by morphometric measurements of $\mathrm{M}$ - and S-cones OS lengths (Figure 5c). Interestingly, cone function was significantly diminished as shown by the light-adapted b-wave amplitudes (Figure 5f) where cone responses were significantly reduced beginning at 8 weeks age. Not surprisingly, scotopic electroretinogram (ERG) responses were diminished over the same time periods reflecting the progressive loss of rod photoreceptors in the $\operatorname{Atg} 5^{\Delta R o d}$ mice (Figures $5 \mathrm{~d}$ and e).

Light-dependent arrestin and transducin translocation in $A \operatorname{tg} 5^{\Delta R o d}$ mice. Light-dependent redistribution of phototransduction proteins such as arrestin and transducin enable photoreceptors to modulate signaling capabilities by changing the concentration of these proteins in the OS. ${ }^{43-45}$ In the dark-adapted state, transducin is localized to the OS and arrestin distributes to the cell body. Light exposure redistributes transducin from the OS to the cell body while arrestin moves to the OS. Defects in the light-dependent translocation of these proteins can result in increased light-induced retinal degeneration. ${ }^{46}$ That light exposure did not accelerate retinal degeneration (Figure 4b) suggests that Atg5-deficient rods may not have defects in phototransduction protein translocation and this was confirmed by examining the light-dependent redistribution of arrestin and transducin (as detected by antibodies to the transducin alpha subunit, $\mathrm{Ta}$ ) in control $\left(A \operatorname{tg} 5^{f /+}:\right.$ Cre $\left.^{+}\right)$and $A \operatorname{tg} 5^{\Delta R o d}$ mice (Figure 6). In the darkadapted state, rod arrestin (red) was distributed throughout the rod cell body and was not co-localized with rhodopsin (green) in the OS of either strain (Figure 6a, left panels). In the light, arrestin moved to OS co-localizing with rhodopsin in both strains (Figure 6a, right panels). Ta (red) localized to the OS in the dark (co-localizing with rhodopsin) (Figure 6b, left panels), but was translocated upon light exposure in both strains (Figure 6b, right panels). Single channel images for these micrographs are presented in Supplementary Figure 2.

Autophagy regulates the level of rod Ta. The $a$-subunit of Ta mediates phototransduction between light-activated rhodopsin and the effector enzyme cGMP phosphodiesterase leading to depolarization in rod cells and the initiation 


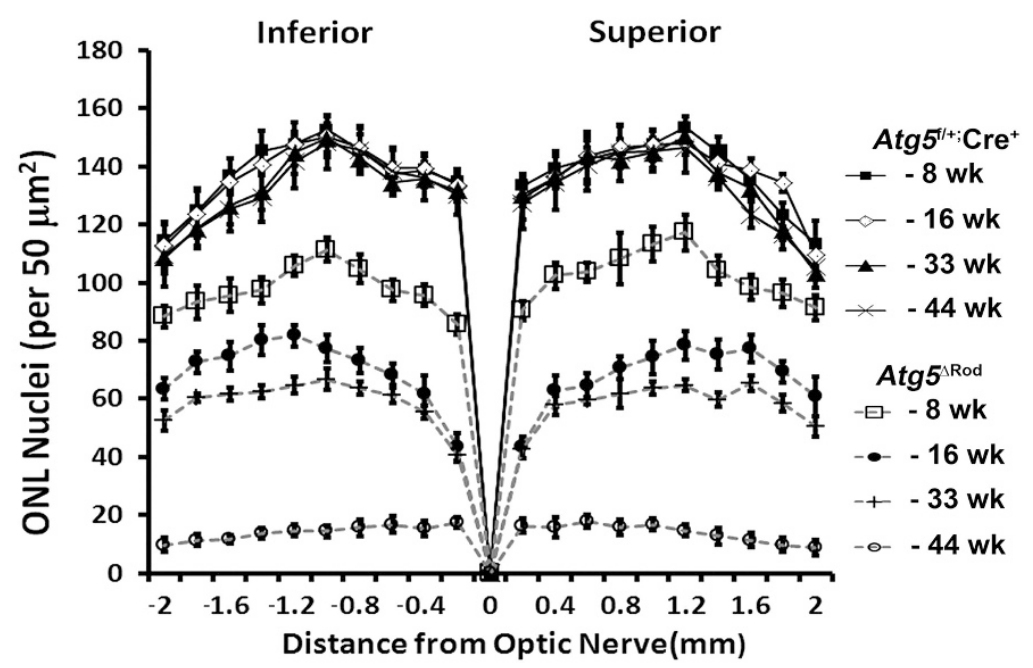

b
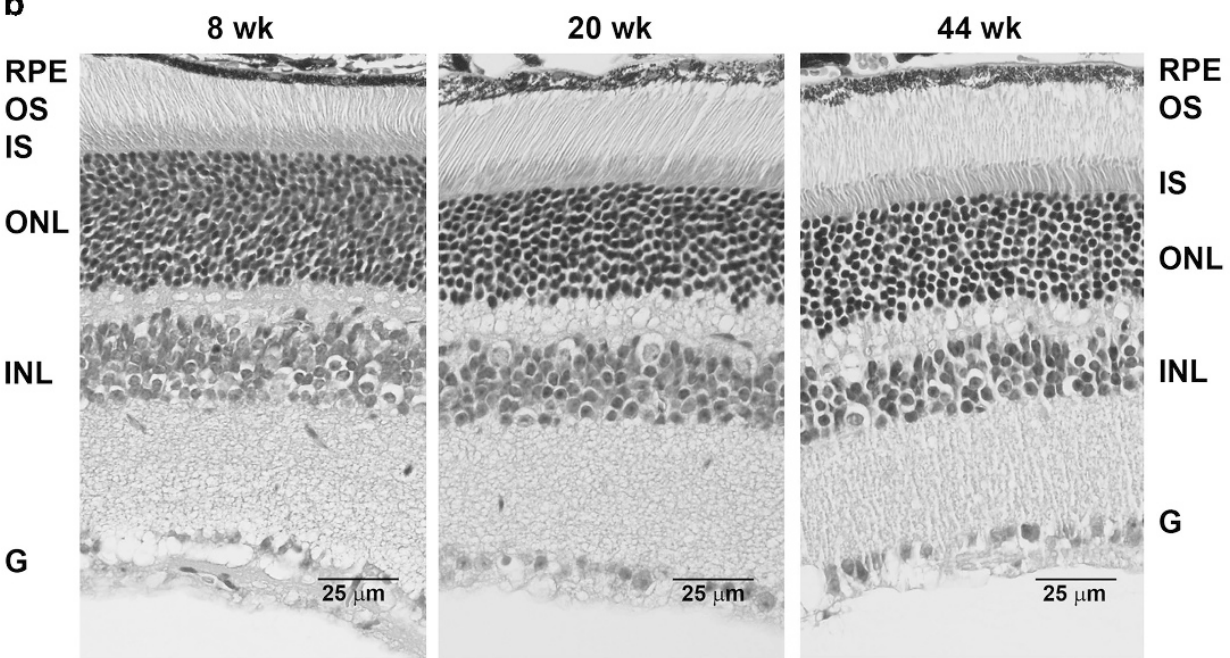

C
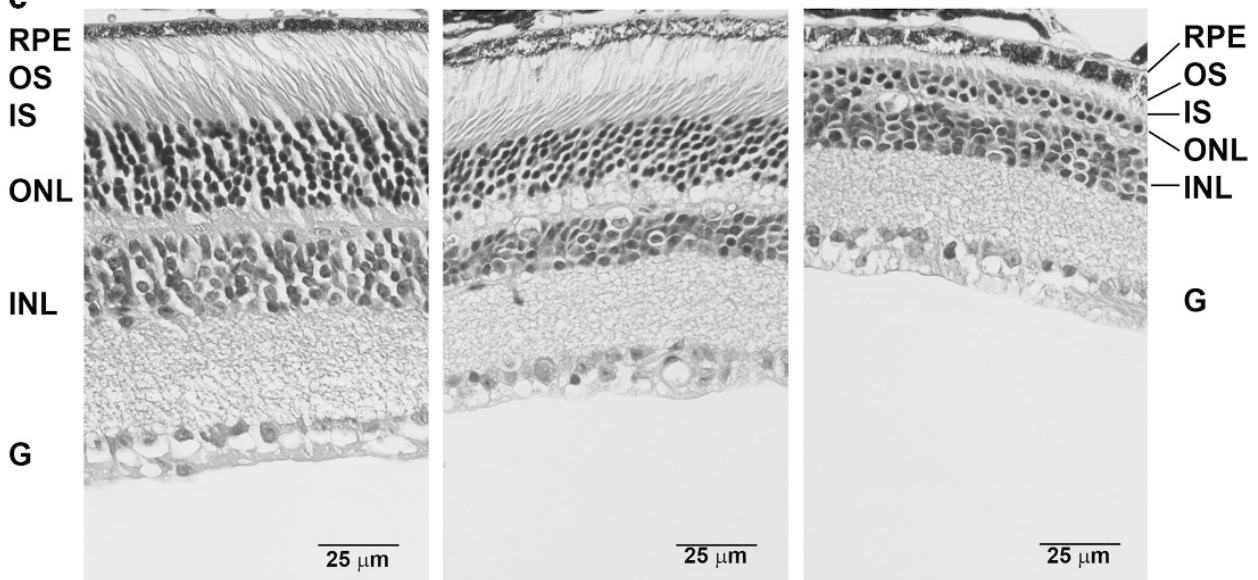

or
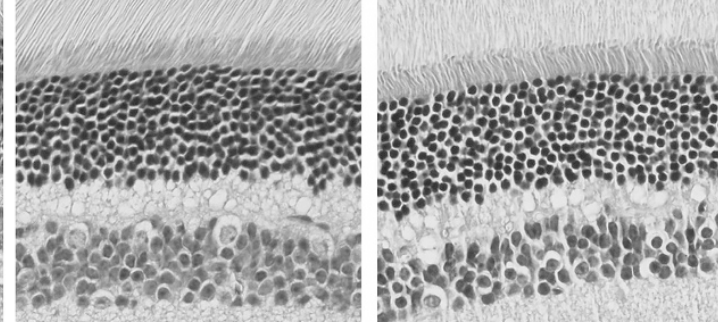

INL

IS
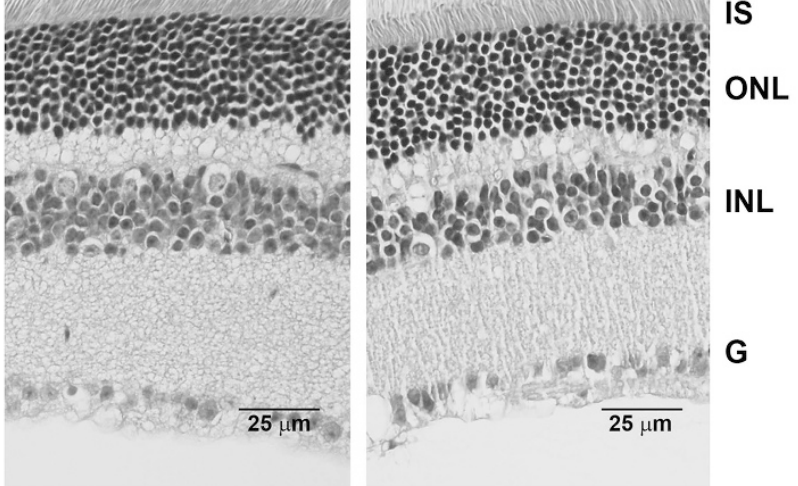

G
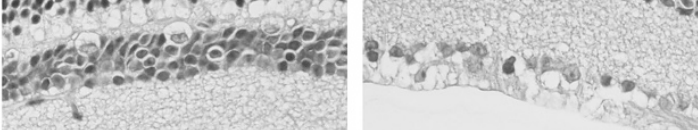

-INL

G

Figure 2 Morphological changes in the retina of $A \operatorname{tg} 5^{\Delta \text { Rod }}$ mice. (a) ONL counts in $A \operatorname{tg} 5^{\Delta \text { Rod }}$ and control $\left(A \operatorname{Atg} 5^{f /+} ; \operatorname{Cre}^{+}\right)$mice at 8, 16, 33 and 44 weeks of age. Representative hematoxylin and eosin sections of (b) control $\left(A \operatorname{tg} 5^{t /+} ; \mathrm{Cre}^{+}\right)$and (c) $A \operatorname{tg} 5^{\Delta \mathrm{Rod}}$ mouse retinae from 8, 20 and 44 weeks of age. IS, inner segments; INL, inner nuclear layer; $\mathrm{G}$, ganglion cell layer 


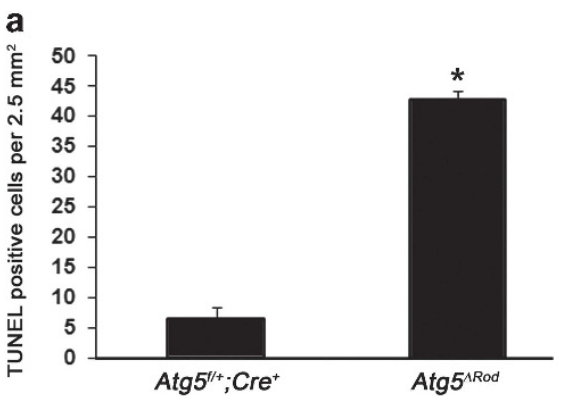

c
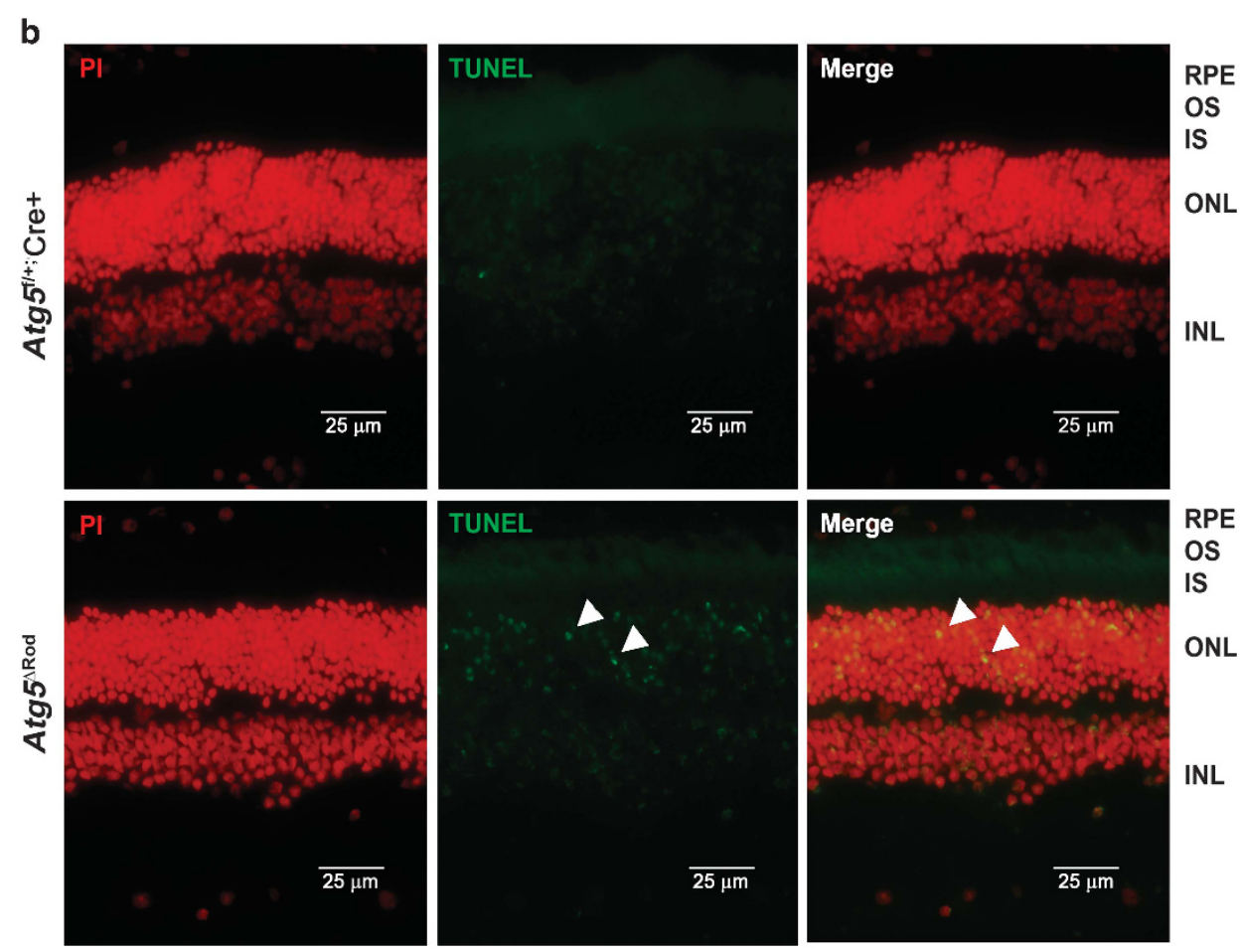

Figure 3 TUNEL-positive cells present in the retina of $A \operatorname{Atg} 5^{\Delta \text { Rod }}$ mice. TUNEL staining was performed on the retinae of 23-week-old Atg $5^{\Delta R o d}$ mice and littermate controls $\left(\right.$ Atg $\left.^{5 /+} ; \mathrm{Cre}^{+}\right)$. (a) Enumeration of TUNEL ${ }^{+}$cells in the $A \operatorname{Atg} 5^{\Delta \text { Rod }}$ and littermate control $\left(\right.$ Atg $^{5 /+} ;$ Cre $\left.^{+}\right)$mice $\left(n=4\right.$ for each group). ${ }^{*}$ denotes statistically different from control $(P<0.05)$. (b) Representative cryosections of $A \operatorname{tg} 5^{\Delta \text { Rod }}$ and control $A t g 5^{f+*} \mathrm{Cre}^{+}$mice. Arrowheads indicate TUNEL ${ }^{+}$cells in the Atg $5^{\Delta \text { Rod }}$ mice that co-label with nuclear stain (PI, propidium iodide). (c) Representative transmission electron microscopy of mouse retina showing condensed nuclear chromatin (right panel, arrow) in the Atg $5^{\Delta \mathrm{Rod}}$ retina that was not observed in the control retina (left panel). IS, inner segments; INL, inner nuclear layer

of the visual cascade. ${ }^{44,47}$ Translocation of transducin from the OS reduces transducin activation in bright light diminishing sensitivity. Although the translocation of transducin was unaffected by the loss of autophagy (Figure 6b), when we examined the relative level of this protein in $\operatorname{Atg} 5^{\Delta R o d}$ mice at 6, 8 and 16 weeks, we noted that as the amount of rhodopsin steadily declined (reflecting the degeneration of rods), the level of Ta remained constant over these time points (Figure 7a). This suggested that $\mathrm{Ta}$ was accumulating as it was not decreasing as the rod photoreceptors died. We confirmed this by quantifying the ratio of $\mathrm{Ta}$ to rhodopsin in four separate experiments (Figure 7b) where the Ta:rhodopsin ratio increased as the rods degenerate. Thus, another possible effect of lost autophagy is inability of the rods to regulate the level of the critical phototransduction protein $\mathrm{Ta}$.

We sought more definitive proof of this possibility by performing additional experiments. It is known that level of transducin is optimal during dark adaptation and that light exposure reduces its levels. ${ }^{48,49}$ Therefore, we asked whether the light-induced reduction in transducin might be related to autophagic degradation by measuring the level of Ta in darkadapted and light-adapted retinae from control and $A \operatorname{tg} 5^{\Delta R o d}$ mice. In control mice $\left(A \operatorname{tg} 5^{f /+} ;\right.$ Cre $\left.^{+}\right)$, Ta levels decreased when the mice are exposed to light in relation to the levels observed after dark-adaptation (Figure 8a), confirming published observations. ${ }^{48,49}$ However, in the Atg $5^{\triangle R o d}$ retina, Ta levels did not vary between light and dark conditions suggesting that Atg5 is necessary to reduce the level of rod transducin in the light-exposed retinae. Quantification of data from four separate experiments is presented in Figure $8 \mathrm{~b}$ confirmed these findings.

We further examined this phenomenon in explant cultures using retinae taken from $\operatorname{Atg}^{f /+} ; \mathrm{Cre}^{+}$and $A \operatorname{tg} 5^{\Delta R o d}$ mice. Whole retinae were removed and placed in culture for $18 \mathrm{~h}$ in the presence or absence of chloroquine, a known inhibitor of lysosomal function and autophagy. Following harvest, western blots for Ta were performed and we monitored p62 as an 
a

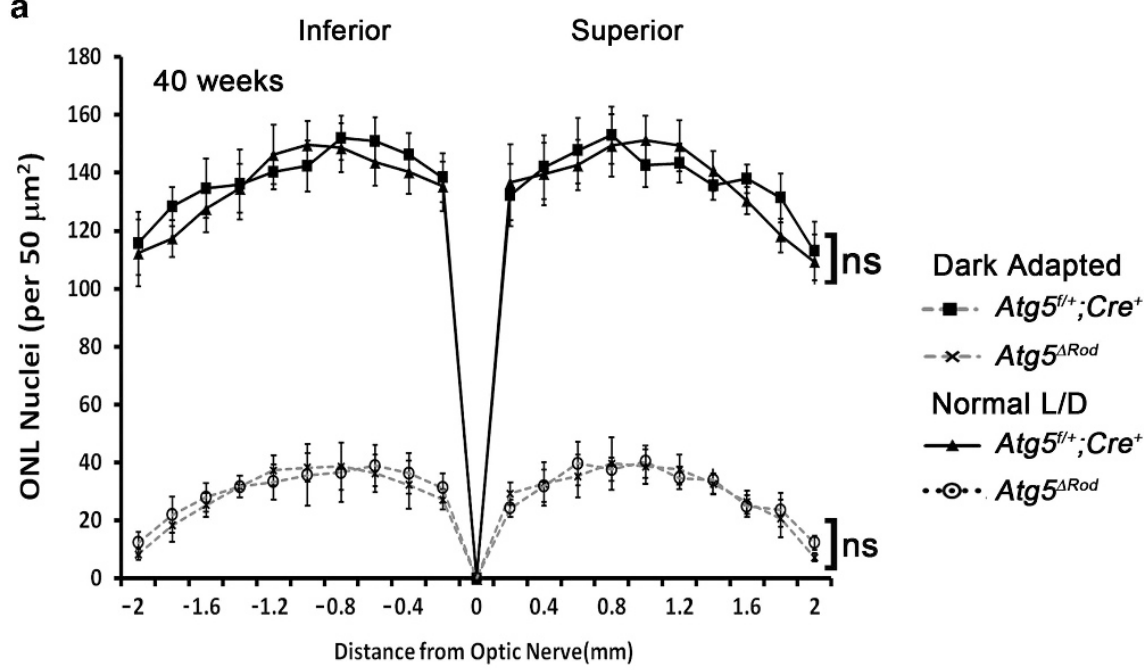

b

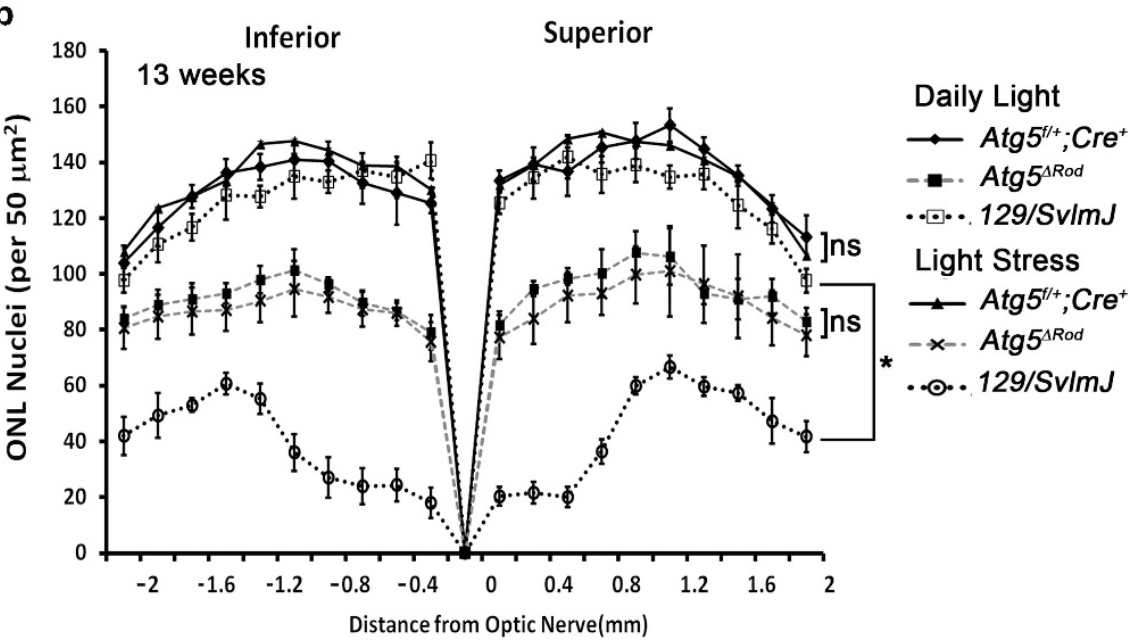

Figure 4 ONL counts in mice following dark adaptation or light stress. (a) $A \operatorname{tg} 5^{\Delta \mathrm{Rod}}$ and control $\left(\operatorname{Atg}^{\mathrm{ft}+} ; \mathrm{Cre}^{+}\right)$mice were dark-adapted from 8 to 40 weeks of age and ONL counts performed. Values were compared with age-matched $A \operatorname{tg} 5^{\Delta \mathrm{Rod}}$ and control $\left(A \operatorname{tg} 5^{t /+} ; \mathrm{Cre}^{+}\right)$littermates that were maintained under normal L/D conditions for the

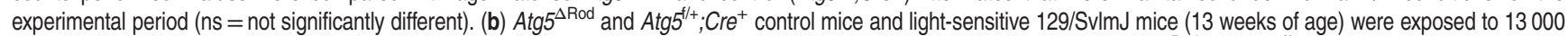

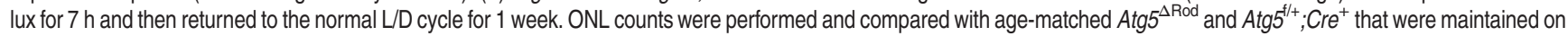
the normal $\mathrm{L} / \mathrm{D}$ cycle for the same experimental period ( $n=3$ for each group). ${ }^{*}$ denotes that there is a significant difference in ONL numbers in the $129 / \mathrm{SvlmJ}$ mice following light stress $(P<0.05)$; (ns = not significantly different)

indicator of the level of autophagic flux. We also tracked the level of rhodopsin in the cultured retinae to be certain that the levels of this protein were not affected by the culture conditions. In untreated cultures of retinae from control mice, Ta levels diminished whereas p62 was not detected indicating a high rate of autophagic flux. However, in the presence of chloroquine, Ta accumulated in control mice, as did p62 (Figure 8c) demonstrating an effective block in autophagy and transducin degradation by the addition of chloroquine. In Atg5deficient rod photoreceptors, the level of Ta was not affected by chloroquine treatment, nor was the level of p62 protein. Figure $8 d$ is the quantification of these results averaged from three separate experiments comparing $\mathrm{Ta}$ with rhodopsin demonstrating that blocking autophagy prevented degradation of Ta. It should also be noted that chloroquine did not affect rhodopsin levels further suggesting that autophagy may not regulate the level of rod opsin.

\section{Discussion}

Inherited retinal diseases are often associated with genetic mutations that generate harmful gene products leading to retinal degenerative disorders. ${ }^{26,30,50,51}$ Our results demonstrate that the lack of autophagy is associated with retinal degeneration even in the absence of such toxic gene products. Our results also highlight the importance of basal autophagy to the long-term survival of the rods suggesting that the recycling functions of this pathway may be providing essential building blocks and energy to support the normal functions of the rods. Autophagy then represents an important pathway that should be considered as a point of therapeutic intervention where survival can be reinforced to inhibit cell death and preserve vision.

Our examination of the $\operatorname{Atg} 5^{\Delta R o d}$ mice revealed three critical findings concerning the importance of autophagy in the light responses of the retina. First, rod degeneration in these mice 
a

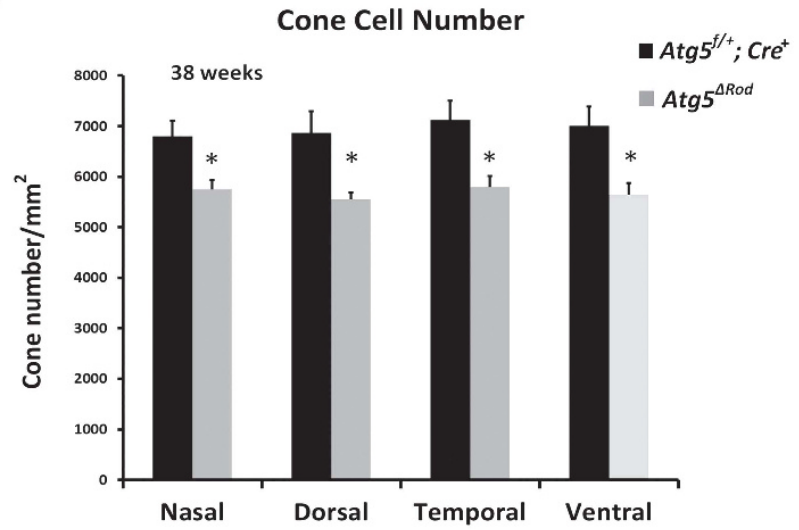

b
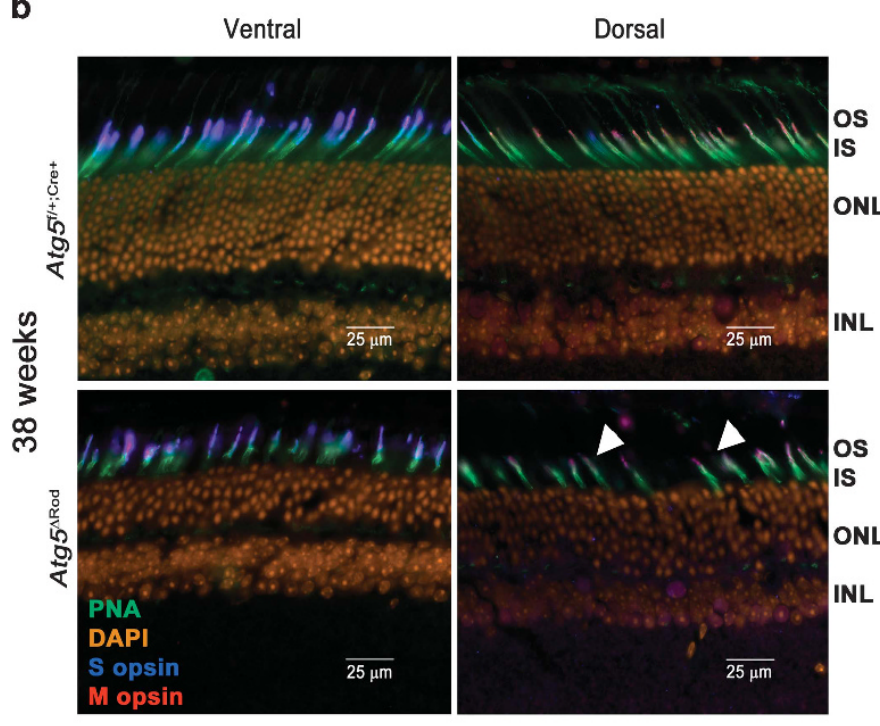

C

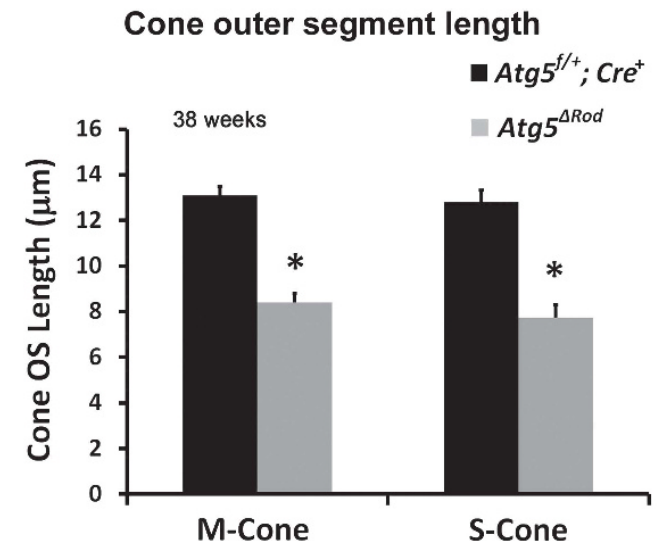

d
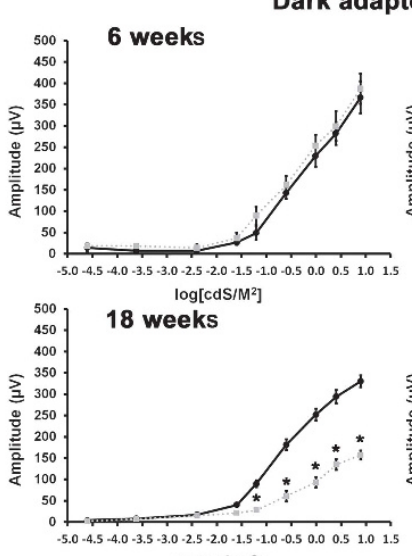

$\log \left[\mathrm{cdS} / \mathrm{M}^{2}\right]$
Dark adapted a-wave
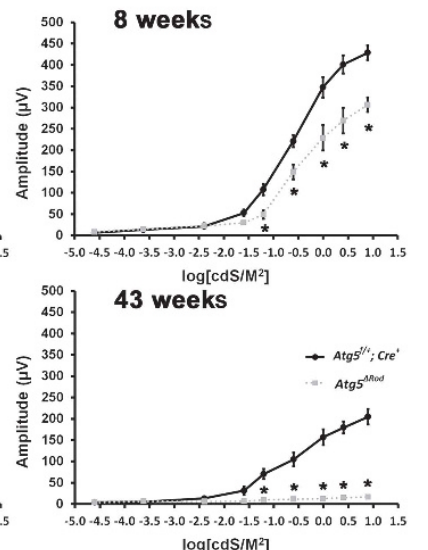

$\log \left[\mathrm{cdS} / \mathrm{M}^{2}\right]$ e
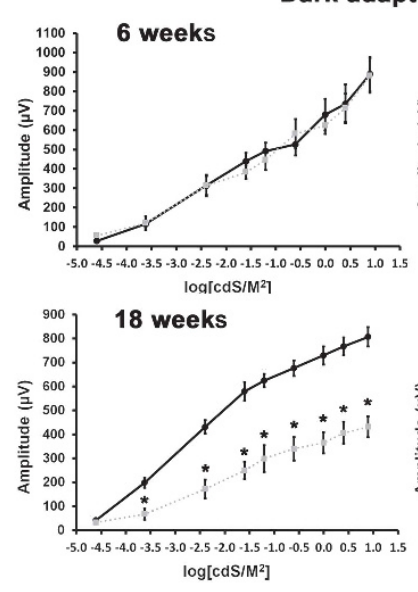

ed b-wave
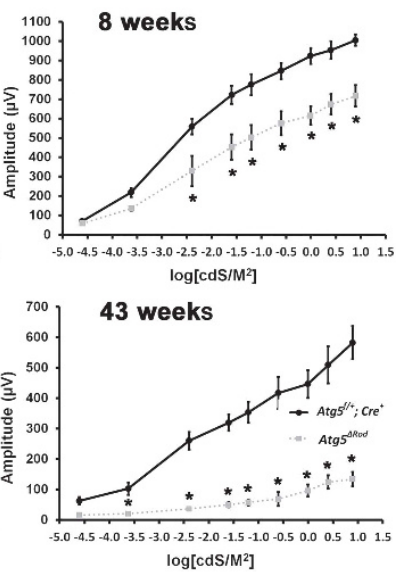

f
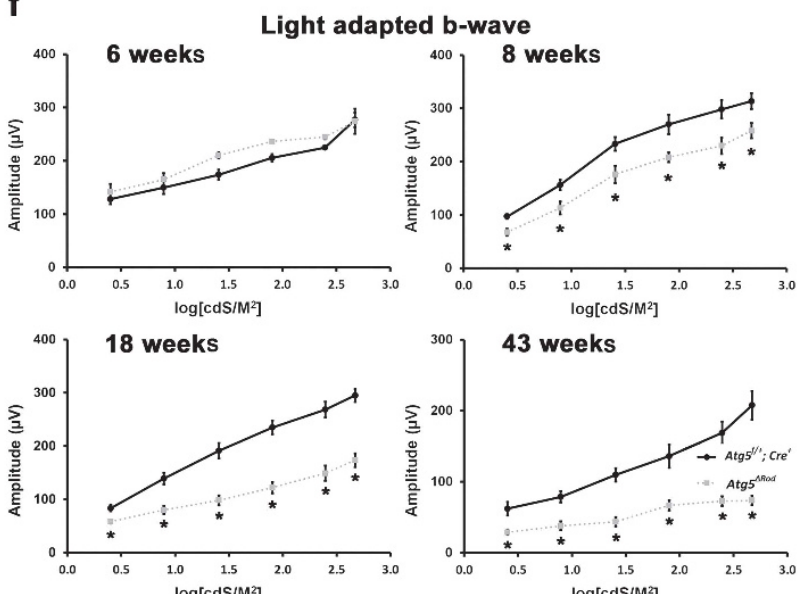

Figure 5 Long-term impact of Atg5-deficient rods on cone photoreceptors. (a) Cone cell counts were performed on the nasal, dorsal, temporal and ventral regions of Atg $5^{\Delta \text { Rod }}$ and control $\left(A \operatorname{tg} 5^{f /+} ; C r e^{+}\right)$mice at 38 weeks of age. ${ }^{*}$ denotes significantly different from littermate control $(P<0.05)(n=3$ for all groups). Representative PNA-stained images for these data are available in Supplementary Figure 1. (b) Representative immunofluorescent images of the dorsal and ventral region of the retina of 38 -week-old mice stained for PNA (green), S-opsin (blue) and M-opsin (red). Arrowheads denote cone OSs in the Atg $5^{\Delta \text { Rod }}$ retina. (c) OS length of M- and S- cones in the mid-dorsal region of the retina from 38-week-old mice. * denotes significantly different from littermate control $(P<0.05)\left(n=3\right.$ for all groups). (d-f) ERG responses in the retina of $A$ tg $5^{\Delta \text { Rod }}$ and control Atg $^{t /+} ;{ }^{-}$Cre ${ }^{+}$mice performed at $6,8,18$ and 43 weeks of age. (d) Dark-adapted a-wave; (e) Dark-adapted b-wave; (f) Light-adapted b-wave. ${ }^{*}$ denotes statistically different from control $(P<0.05)$; n.s. $=$ not significantly different $(n=5$ for each group) 


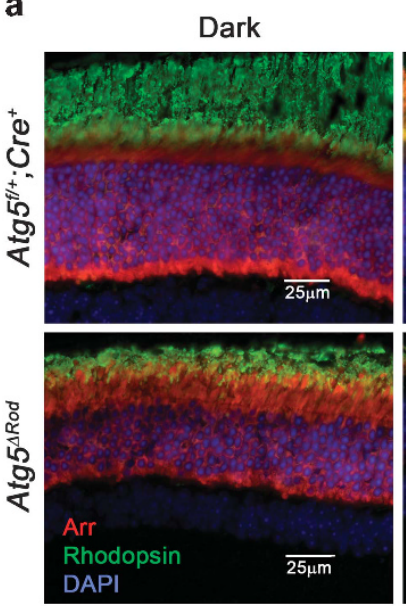

b
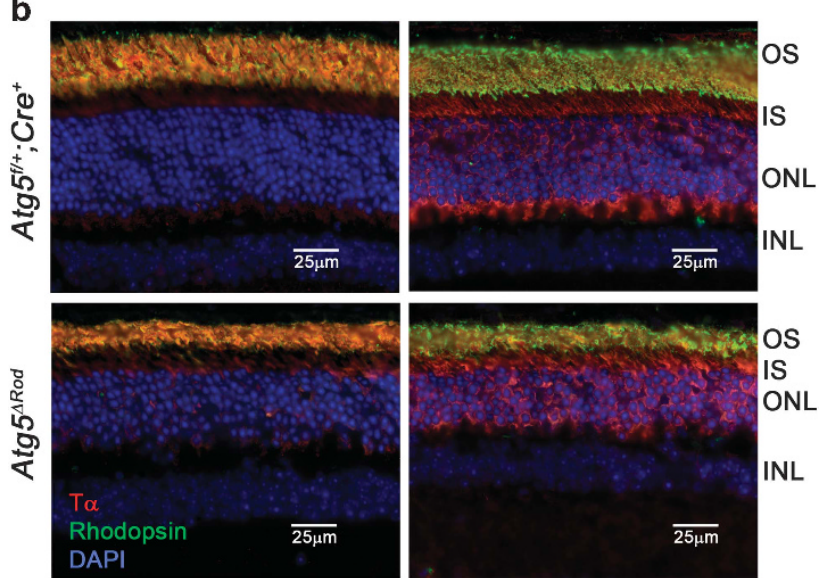

Figure 6 Arrestin (Arr) and T $\alpha$ expression in rod cells. Twenty-three-week-old $A t g 5^{\Delta \text { Rod }}$ mice and littermate control $\left(\mathrm{Atg}^{\mathrm{fl} /} ; \mathrm{Cre}^{+}\right)$mice were either dark-adapted overnight (Dark) or were exposed to 10000 lux (Light) for 90 min after overnight dark adaptation. (a) Representative immunofluorescent images for rod arrestin (Arr). Sections were co-stained for rhodopsin (green) and Arr (red). (b) Representative immunofluorescent images for rod T $\alpha$. Sections were co-stained for rhodopsin (green) and $\mathrm{T} \alpha$ (red). Single channel images are shown in Supplementary Figure 2. IS, inner segments; INL, inner nuclear layer

was independent of daily light exposure as we detected retinal degeneration in the retina of $A \operatorname{tg} 5^{\Delta R o d}$ mice even when the animals were dark-adapted for a long period of time. This further emphasizes the survival functions of autophagy in rods and demonstrates that it is independent of the light-sensing functions of the retina.

Second, autophagy does not appear to have a role in the resistance of the retina to the damaging effects of intense light. We had hypothesized that if autophagy were a critical process for resisting light-induced damage that inhibiting this pathway in the light-stress-resistant C57BL/6J strain ${ }^{41,42}$ would make them more susceptible to damage. This was not the case as we could not accelerate rod degeneration by intense light exposure of the $A \operatorname{tg} 5^{\Delta R o d}$ mice. This finding contrasts a recent study by Chen et al., ${ }^{33}$ who reported that deletion of the essential autophagy gene Atg7 increased the sensitivity of rods to light-induced damage. We utilized nearly three times the light intensity used in that study (5000 lux versus 13000 a

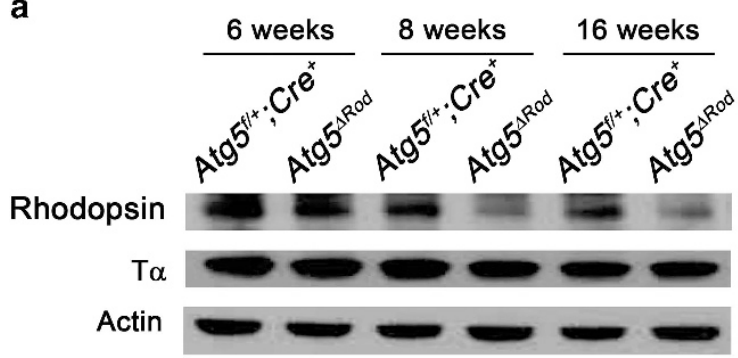

b

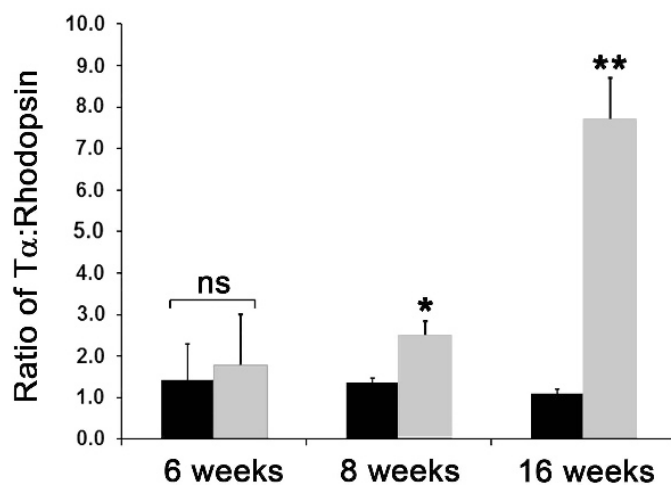

Figure 7 Expression of $\mathrm{T} \alpha$ in the retina of $A \operatorname{tg} 5^{\Delta R o d}$ mice. (a) Representative western blots for retinal samples from $\mathrm{Atg}^{\mathrm{ARod}}$ and control $\left(\mathrm{Atg}^{\mathrm{ft}}{ }^{\mathrm{t}} ; \mathrm{Cre}{ }^{+}\right)$mice performed at 6, 10 and 16 weeks of age. Analysis was performed for rhodopsin, T $\alpha$ and actin. (b) Densitometric analysis of the relative expression levels of T $\alpha$ compared with rhodopsin in $A \operatorname{tg} 5^{\Delta \text { Rod }}$ mice and control $\left(A \operatorname{tg} 5^{f / t} \mathrm{Cre}^{+}\right)$mice. Bars represent the average ratio of four separate experiments. n.s. $=$ not significantly different, ${ }^{*}$ denotes statistically different from control $(P<0.05)$, ${ }^{*}$ denotes statistically different from control $(P<0.01)$

lux in our studies) and exposed the animals for a longer period of time ( $2 \mathrm{~h}$ versus $7 \mathrm{~h}$ in our studies) and degeneration was still not observed. It is unlikely that the difference lies in the autophagy gene targeted (Atg7 versus Atg5); however, these authors did use a different Cre-expressing strain (LMOP-Cre ${ }^{52}$ versus iCre-75 stain ${ }^{53}$ ) so we cannot rule out effects of differential Cre-expression. Another important difference may lie in the background of the mice utilized as these authors used mice that had an accelerated visual cycle because of the presence of Leu-450 the RPE protein, ${ }^{33}$ which can increase light-induced degeneration. ${ }^{41}$ It is also noteworthy that the rodspecific deletion of $A t g 7$ in that study did not lead to retinal degeneration in the absence of light stress ${ }^{33}$ as did the rodspecific deletion of Atg5 presented here.

A third insight into the role of autophagy in the light-sensing functions of the rods comes from our study of rhodopsin and the visual transduction proteins arrestin and transducin. Autophagy is well known to regulate the turnover of cytosolic proteins by removing damaged or misfolded proteins. ${ }^{14,54}$ In the retina, autophagy has been proposed to regulate the level of rhodopsin; ${ }^{39,40}$ however, we did not observe accumulation of rhodopsin in the rods of $A \operatorname{tg} 5^{\Delta R o d}$ mice nor did we observe rhodopsin accumulation when autophagy was blocked in retinal explant cultures (Figures $8 \mathrm{c}$ and $\mathrm{d}$ ). These results show that autophagy may not directly regulate rhodopsin levels in rods.

Although we did not observe an effect on arrestin and transducin translocation in light and dark, we did observe that rod $\mathrm{Ta}$ accumulated in Atg5-deficient rods as they 


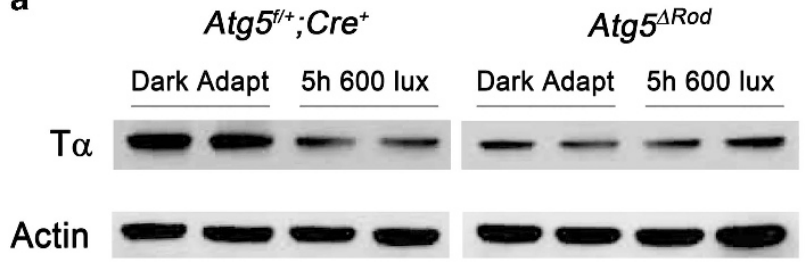

b

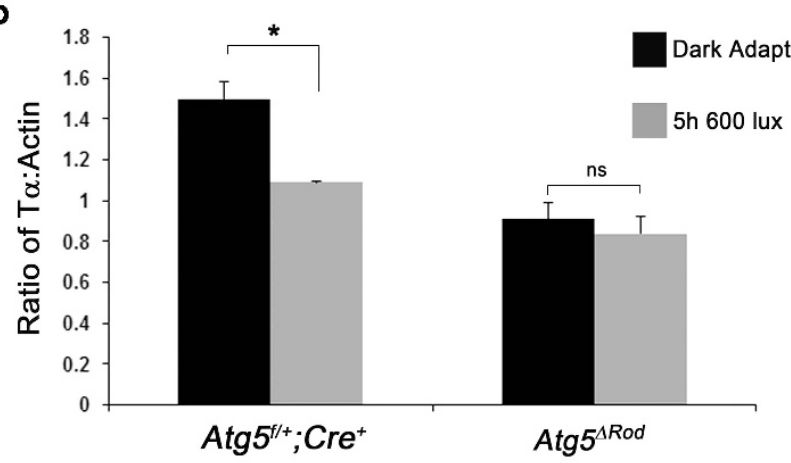

c

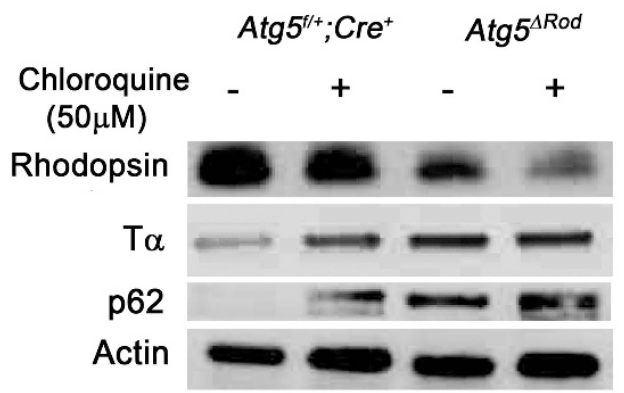

d

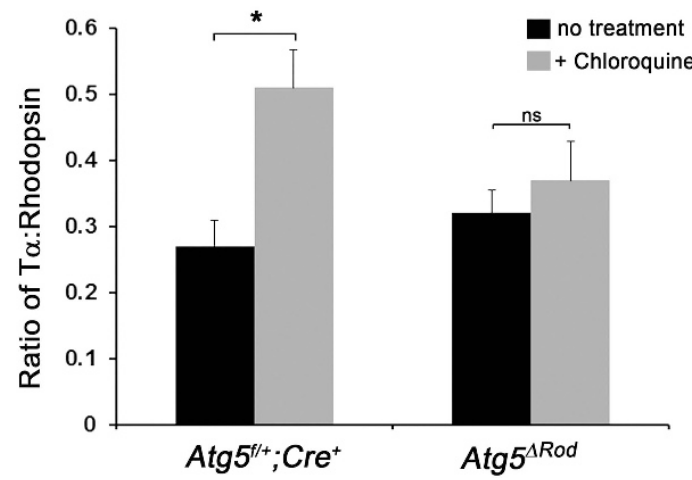

Figure 8 Regulation of $\mathrm{T} \alpha$ in the retina by autophagy. (a) Representative western blots for retinal samples from 12-week-old $\mathrm{Atg}^{\Delta \mathrm{Rod}}$ and control $\left(\mathrm{Atg}^{\mathrm{ft}} ; \mathrm{Cre}^{+}\right)$mice that were dark-adapted overnight or exposed to 600 lux room light for $5 \mathrm{~h}$. (b) Densitometric analysis of the relative expression levels of $T \alpha$ to actin. Bars represent the average ratio of three separate experiments. (c) Representative western blots from 12-week-old Atg $5^{\Delta \text { Rod }}$ and control $\left(\mathrm{Atg}^{5 /+} ; \mathrm{Cre}^{+}\right)$retinal explants obtained after overnight culture with or without chloroquine $(50 \mu \mathrm{m})$. Blots were probed for actin, rhodopsin, T $\alpha$ and p62. (d) Densitometric analysis of the relative expression levels of T $\alpha$ compared with rhodopsin in treated and non-treated samples averaged for three separate experiments. * denotes statistically different from control $(P<0.05), \mathrm{ns}=$ not significantly different

degenerated suggesting that autophagy is involved in the turnover of this protein. Light sensitivity in rod photoreceptors is set by the rate of transducin activation and depends on the concentration of transducin in the photoreceptor OS. Our results demonstrate that autophagic degradation can regulate the concentration of transducin and indicate that this process may be an additional mechanism whereby rod photoreceptors regulate their sensitivity to light stimuli.

Although our data suggest that the death of the rods in the Atg $5^{\Delta R o d}$ mice is via apoptosis, we do not yet know the mechanism by which death is initiated. The importance of autophagy in maintaining nutrient and energy supplies in cells ${ }^{7}$ suggests that the rods may be starving to death. However, it is notable that degeneration took a number of months to be completed, implying a compensatory mechanism. It was recently reported that the age-dependent decrease in macroautophagy in the retina was accompanied by a concomitant increase in CMA to help preserve the retina. ${ }^{22}$ We found no evidence for increased CMA in retina when Atg5 was deleted in rods as determined by measuring the levels of Lamp2A and Hsc70. It should be noted that in this previous study involving retinal aging, Atg5 was deleted using a NestinCre that deletes Atg5 in all neural precursors beginning at embryonic day $10.5 .^{54}$ Neuronal cell deletion of essential autophagy genes causes many neurological and developmental defects in the mice. ${ }^{54}$ Thus, in the retina, Atg5 deletion would occur in rods, Mueller cells, RPE cells, cones, ganglion cells, bipolar cells, etc. making it difficult to determine whether the degenerative effects on the retina or the increase in CMA observed by these authors ${ }^{22}$ were the result rod photoreceptor-specific deletion of Atg5 or the cumulative effects of Atg5 deficiency in the other cell types.

The loss of autophagy led to the near complete loss of rods; however, we noted that cones were mostly preserved, but their function was significantly impaired. Although we do not know the reason for this observation, our results imply that the death of the rods may not be sufficient to induce cone death as reported in other models of retinal degeneration. ${ }^{26,30,50,51}$ However, our results do suggest that function of the cones may be intimately tied to that of the rods and that methods to boost cone function would significantly improve visual acuity in patients with rod-specific disease-causing mutations.

\section{Materials and Methods}

Mice. Rhodopsin-iCre-75 transgenic mice ${ }^{53}$ (provided by Dr Jason Chen, Baylor College of Medicine) were crossed to the Atg $5^{\text {flox filox }}$ (provided by Dr Noboru Mizushima, Tokyo Medical and Dental University) $)^{54}$ to generate the $A \operatorname{tg} 5^{\Delta R o d}$ mouse line in which Atg5 was specifically deleted in rod cells. Atg ${ }^{\Delta \text { Rod }}$ offspring are born viable, in reasonable numbers, and do not show any developmental defects in the eye or other organs at birth (data not shown). All transgenic and conditional knockout lines were crossed to the C57BL/6J (strain \#000664, Jackson Laboratories, Bar Harbor, ME, USA) and verified as congenic to C57BL/6J by microsatellite analysis (Research Animal Diagnostic and Investigative Laboratory, RADIL, University of Missouri, Columbia, MO, USA). In addition, they were free of the rd8 mutation by PCR analysis. ${ }^{55} 129 /$ SvImJ mice (strain \# 002448) were purchased from Jackson Laboratories. Mice were housed in a barrier facility operated under standard $12 \mathrm{~h}$ light/12 $\mathrm{h}$ dark cycle (referred to as normal $\mathrm{L} / \mathrm{D}$ ) with the luminance ranging from 60 to 100 lux during the daily/light cycle. Facilities are maintained by the Division of Comparative Medicine of Washington University School of Medicine. Experiments were carried out in strict accordance with recommendations in the Guide for the Care and Use of Laboratory Animals of the National Institutes of Health $(\mathrm{NIH})$, in accordance with the ARVO Resolution on the Use of Animals for Ophthalmic Research, and approved by the Washington University Animal Studies Committee. In all experiments, littermates were used $\left(\operatorname{Atg}^{5 /+;} \mathrm{Cre}^{+}\right.$or $\left.\operatorname{Atg}^{t / f}\right)$ as controls and experiments contained at least three mice per group. Each experiment was repeated a minimum of three times. 
Antibodies. For western immunoblot analysis, the following antibodies were used: actin-HRP (1:3000, sc-1815), anti-SQSTM1 (1:250, sc-25575), anti-Gnat1 $(\mathrm{T} \alpha)$ (1:2000, sc-389) from Santa Cruz Biotechnology (Paso Robles, CA, USA); anti-Rhodopsin (1:3000- AB5356) from Millipore (Danvers, MA, USA); anti-LC3B (1:2000, L7543), anti-ATG5/N-terminal (1:1000, A0851), from Sigma Aldrich (St Louis, MO, USA); anti-Lamp2A (1 : 1000, ab18528) from Abcam (Cambridge, MA USA); anti-Hsc70 (1: 2000, ADI-SPA-820) from Enzo Life Sciences (Farmingdale, NY, USA) anti-rabbit-HRP $(1: 3000$, \#7074S) from Cell Signaling Technologies (Danvers, MA, USA); anti-mouse-HRP (1:5000, \#554002) from BD Biosciences (Torrance, CA, USA). The following antibodies were used for immunofluorescence staining: anti-M opsin $(1: 200$, AB5405) and anti-rhodopsin $(1: 200$, AB5356) from Millipore; anti-S opsin (1:100, sc-14363), anti-Gnat1 (To) (1:200,sc-389), antiarrestin (1:100,sc-34547) from Santa Cruz Biotechnology; anti-rabbit AlexaFluor 594 (1:300, A21207), anti-goat AlexaFluor 647 (1:300, A21447) from Life Technologies (Grand Island, NY, USA).

Electroretinogram. ERGs on Atg5 $5^{\Delta R o d}$ and age-matched littermate control mice were performed as previously described. ${ }^{34}$ Briefly, mice were dark-adapted overnight and anesthetized by intraperitoneal injection of mouse cocktail $(86.9 \mathrm{mg} / \mathrm{kg}$ ketamine and $13.4 \mathrm{mg} / \mathrm{kg}$ xylazine diluted in PBS). After pupil dilation $(10 \%$ phenylephrine hydrochloride and $1 \%$ tropicamide), full-field scotopic ERGs were recorded using a Tucker-Davis System 3 Complete ABR/OAE Workstation (TuckerDavis Technologies, Alachua, FL, USA). Photopic ERGs were recorded after light adaptation for $10 \mathrm{~min}$

Histological analysis. Eyes were removed and fixed in $4 \%$ paraformaldehyde overnight at $4{ }^{\circ} \mathrm{C}$. Tissues were then embedded in paraffin and sagittal sections of $5 \mu \mathrm{m}$ thickness were cut and stained with hematoxylin and eosin.

Transmission electron microscopy. Mice were deeply anesthetized with Ketamine/Xylazine and fixed by intracardiac perfusion with a quick rinse of $0.1 \%$ Heparin in $0.1 \mathrm{M}$ sodium phosphate buffer followed by $2 \%$ paraformaldehyde $/ 2.5 \%$ glutaraldehyde in $0.1 \mathrm{M}$ phosphate buffer (pH 7.35). Eyes were removed and immersion-fixed overnight in the same fixative, post-fixed in $1 \%$ osmium tetroxide for $1 \mathrm{~h}$ and stained en bloc with $1 \%$ uranyl acetate in $0.1 \mathrm{M}$ acetate buffer for $2 \mathrm{~h}$. Blocks were then dehydrated in a graded series of ethanol followed by propylene oxide, and embedded in Araldite 6005/EMbed 812 resin (Electron Microscopy Sciences, Hatfield, PA, USA). Semi-thin sections $(0.5-1 \mu \mathrm{m})$ were cut through the entire retina at the level of the optic nerve and stained with toluidine blue. Ultra-thin sections were taken from a $600-800 \mu \mathrm{m}$ length of retina where the majority of inner segments were oriented longitudinally; samples from the same areas were matched between control and experimental animals. Ultra-thin sections were then poststained with uranyl acetate and lead citrate, viewed on a Hitachi $\mathrm{H} 7500$ electron microscope (Wallingford, CT, USA) and documented in digital images.

Immunofluorescence staining. Eyes were removed and fixed in $4 \%$ paraformaldehyde overnight at $4{ }^{\circ} \mathrm{C}$. They were then transferred to $30 \%$ sucrose/PBS at $4{ }^{\circ} \mathrm{C}$ overnight and then embedded in O.C.T. Compound (TissueTek, Torrance, CA, USA). Sagittal cryosections of $7 \mu \mathrm{m}$ thickness were cut. Sections were placed in blocking buffer (10\% donkey serum, 2\% BSA, 0.2\% Triton X-100 in PBS) for $2 \mathrm{~h}$ at RT and then incubated with primary antibodies in dilution buffer (2\% donkey serum, $0.2 \%$ Triton X-100 in PBS) overnight at $4^{\circ} \mathrm{C}$ followed by secondary fluorescent-labelled antibodies in dilution buffer for $2 \mathrm{~h}$ at RT. Visualization of cone cells was achieved by incubating sections with a mix of primary antibodies and AlexaFluor 488-conjugated PNA (Life Technologies) overnight at $4{ }^{\circ} \mathrm{C}$ followed by secondary antibodies as described. Nuclei were stained with DAPI present in the mounting media SlowFade Gold (Life Technologies). Images were acquired using Olympus Fluoroview FV1000 confocal microscope (Olympus America Inc., Center Valley, PA, USA).

Light stress and dark adaptation. Light stress experiments were performed on mice that were dark-adapted overnight. Cyclopentolate hydrochloride (1\%; Alcon, Fort Worth, TX, USA) was used to temporarily stop the eye from focusing and to dilate the pupil. Pupils were then further dilated with $2.5 \%$ phenylephrine hydrochloride and the mice were exposed to 13000 lux of white light for $7 \mathrm{~h}$, with reapplication of phenylephrine every $2 \mathrm{~h}$. The mice were then returned to the normal L/D cycle for 1 week. In transducin and arrestin translocation studies, mice were dark-adapted over night and eyes were harvested in dim red light to localize the molecules. Light adaptation was performed by placing dark adapted animals in 10000 lux of white light for 90 min prior to harvest. Following dark and light adaptation, the mice were anesthetized by i.p. injection of a mixture of $86.9 \mathrm{mg} /$ $\mathrm{kg}$ ketamine and $13.4 \mathrm{mg} / \mathrm{kg}$ xylazine diluted in PBS. Eyes were enucleated and processed for histological analysis.

Prolonged dark adaption studies were performed by placing 8-week-old $\operatorname{Atg}^{f /+} \mathrm{Cre}^{+}$and $\mathrm{Atg} 5^{\Delta \text { Rod }}$ mice in a dark room (no white light) until they were 40 weeks old. Cages, water bottles and food were changed under dim red light.

SDS-PAGE and western blot analysis. Briefly, retinae were removed from enucleated eyes and placed in ice-cold lysis buffer (10 mM Tris (pH7), $30 \mathrm{mM}$ sodium pyrophosphate, $1 \mathrm{mM}$ sodium fluoride, $1 \mathrm{mM}$ sodium vanadate, $50 \mathrm{mM}$ sodium chloride, $1 \%$ Triton X-100) containing $1 \times$ protease inhibitor cocktail (Roche Diagnostics, Indianapolis, IN, USA) then homogenized and insoluble material removed by centrifugation for $10 \mathrm{~min}$ at $12000 \times \mathrm{g}$ at $4^{\circ} \mathrm{C}$. Protein concentration was determined using a Pierce BCA assay kit (ThermosScientific, Rockford, IL, USA). Retina samples (either $25 \mu \mathrm{g}$ or $15 \mu \mathrm{g}$ ) were separated on a $12 \%$ Bis-Tris NuPage gel (Life Technologies) transferred to Immobulon FL membranes (Millipore), blocked for $1 \mathrm{~h}$ at RT in $5 \%$ non-fat milk powder in TBS pH 7.4 with $0.1 \%$ Tween 20 (TBST), incubated with primary antibodies in $5 \%$ BSA-TBST overnight at $4{ }^{\circ} \mathrm{C}$ followed by incubation with corresponding secondary peroxidase-conjugated antibodies in 5\% BSA-TBST for $1 \mathrm{~h}$ at RT. Immunoreactive bands were visualized using SuperSignal West Pico (ThermoScientific, Rockford, IL, USA) chemiluminescence and exposing to autoradiographic film. Alpha-Imager software was used to quantify the density of bands relative to actin loading control. T $\alpha$ levels were normalized relative to rhodopsin expression levels in Figure 7 and to actin in Figure 8.

TUNEL staining. TUNEL assays were performed on cryosections prepared as above and stained using a fluorescent TUNEL kit (\#17-141, Millipore) per the manufacturer's protocol. Enumeration of TUNEL-positive cells was performed by capturing four to five images per section (two sections per sample) using an Olympus BX51 fluorescence microscope and counting the number of positive cells per field.

Enumeration of the ONL and cone counts. Photoreceptor nuclei in the ONL were counted in sagittal cut cryosections that were stained with the nuclear stain DAPI. Images were captured using an Olympus BX51 fluorescence microscope, and cell nuclei counted using the Image $\mathrm{J}$ software in an area of $50 \mu \mathrm{m} \times 50 \mu \mathrm{m}$ at $200 \mu \mathrm{m}$ intervals from the optic nerve head in the superior and inferior regions. Data are expressed as the nucleus number per $50 \mu \mathrm{m}^{2}$.

Enumeration of cone cells was performed on retinal tissue that was carefully dissected to separate it from the underlying RPE, choroid and sclera. Retinae were stained with AlexaFluor 488-conjugated PNA overnight at $4{ }^{\circ} \mathrm{C}$ and radial cuts (average, four) were made from the edge of the retinal tissue towards the center of the retina, then flat-mounted onto slides with the photoreceptor OSs facing up. Cone cells were then counted in three non-overlapping fields with an area of $0.0616 \mathrm{~mm}^{2}$, each field at a location midway between the optic nerve head and the retinal margin, using images collected with an Olympus BX51 fluorescent microscope. Data are expressed as average cell number $/ \mathrm{mm}^{2}$.

Cone cell length was determined by staining cryosections with AlexaFluor 488conjugated PNA (Life Technologies) to identify the cones and anti-M and -S opsin antibodies to locate the OSs. Individual cone OS lengths were then measured using images collected with an Olympus BX51 fluorescent microscope using the MetaMorph software (Molecular Devices, Sunnyvale, CA, USA). Data are expressed in micrometers.

Explant cultures. Enucleated eyes were placed in Dulbecco's PBS containing $100 \mathrm{U} / \mathrm{ml}$ penicillin and $100 \mu \mathrm{g} / \mathrm{ml}$ streptomycin for $10 \mathrm{~min}$ on ice. The cornea was then carefully cut away and lens removed before the retinae were gently pealed away from the underlying RPE and choroid. Retinae were then placed in RPMI-1640 medium (Life Technologies) containing 10\% FBS, $100 \mathrm{U} / \mathrm{ml}$ penicillin and $100 \mu \mathrm{g} / \mathrm{ml}$ streptomycin with or without $50 \mu \mathrm{M}$ chloroquine (Sigma) and cultured overnight at $37^{\circ} \mathrm{C}$ with $5 \% \mathrm{CO}_{2}$. Retinae were then rinsed with ice-cold PBS, and placed in fresh ice-cold PBS for 5 min before being placed in ice-cold lysis buffer and prepared for western blot analysis as described above.

Statistical analysis. All data were analyzed using a two-tailed, unpaired Student's $t$ test. Statistical significance was considered as $P<0.05$ and indicated by an asterisk. n.s. denotes not significant. Error bars represent mean \pm standard error (S.E.).

\section{Conflict of Interest}

The authors declare no conflict of interest. 
Acknowledgements. We would like to thank Frank Schottler for his assistance with transmission electron microscopy. This work was supported by a National Institutes of Health Grants EY015570 (TAF), EY019287 (RSA), EY02687 (Department of Ophthalmology and Visual Science Core Grant), a Department of Ophthalmology and Visual Science unrestricted grant from Research to Prevent Blindness, New York, NY, Research to Prevent Blindness Inc. Career Development Award and Physician Scientist Award (RSA), Carl Marshall Reeves and Mildred Almen Reeves Foundation Inc. Award (RSA and TAF) and The BrightFocus Foundation, Clarksburg, MD (TAF).

1. Choi AM, Ryter SW, Levine B. Autophagy in human health and disease. N Engl J Med 2013; 368: 1845-1846.

2. Schneider JL, Cuervo AM. Autophagy and human disease: emerging themes. Curr Opin Genet Dev 2014; 26C: 16-23.

3. Rubinsztein DC, Marino G, Kroemer G. Autophagy and aging. Cell 2011; 146: 682-695.

4. Green DR, Galluzzi L, Kroemer G. Mitochondria and the autophagy-inflammation-cell death axis in organismal aging. Science 2011; 333: 1109-1112.

5. Liu S, Hartleben B, Kretz O, Wiech T, Igarashi P, Mizushima N et al. Autophagy plays a critical role in kidney tubule maintenance, aging and ischemia-reperfusion injury. Autophagy 2012; 8: 826-837.

6. Kuma A, Mizushima N. Physiological role of autophagy as an intracellular recycling system: with an emphasis on nutrient metabolism. Semin Cell Dev Biol 2010; 21: 683-690.

7. Mizushima N, Komatsu M. Autophagy: renovation of cells and tissues. Cell 2011; 147: 728-741.

8. Degterev A, Huang Z, Boyce M, Li Y, Jagtap P, Mizushima N et al. Chemical inhibitor of nonapoptotic cell death with therapeutic potential for ischemic brain injury. Nat Chem Bio 2005; 1: 112-119.

9. Komatsu M, Waguri S, Chiba T, Murata S, Iwata J, Tanida I et al. Loss of autophagy in the central nervous system causes neurodegeneration in mice. Nature 2006; 441: 880-884

10. Nishiyama J, Miura E, Mizushima N, Watanabe M, Yuzaki M. Aberrant membranes and double-membrane structures accumulate in the axons of Atg5-null Purkinje cells before neuronal death. Autophagy 2007; 3: 591-596.

11. Hartleben B, Godel M, Meyer-Schwesinger C, Liu S, Ulrich T, Kobler S et al. Autophagy influences glomerular disease susceptibility and maintains podocyte homeostasis in aging mice. J Clin Invest 2010; 120: 1084-1096.

12. Rubinsztein DC, Codogno $P$, Levine B. Autophagy modulation as a potential therapeutic target for diverse diseases. Nat Rev Drug Discov 2012; 11: 709-730.

13. Wong E, Cuervo AM. Autophagy gone awry in neurodegenerative diseases. Nat Neurosci 2010; 13: 805-811.

14. Harris $\mathrm{H}$, Rubinsztein DC. Control of autophagy as a therapy for neurodegenerative disease. Nat Rev Neurol 2012; 8: 108-117.

15. Nixon RA. The role of autophagy in neurodegenerative disease. Nat Med 2013; 19: 983-997.

16. Rivera JF, Costes S, Gurlo T, Glabe CG, Butler PC. Autophagy defends pancreatic beta cells from human islet amyloid polypeptide-induced toxicity. J Clin Invest 2014; 124: 3489-3500.

17. Shigihara N, Fukunaka A, Hara A, Komiya K, Honda A, Uchida T et al. Human IAPP-induced pancreatic beta cell toxicity and its regulation by autophagy. J Clin Invest2014; 124: 3634-3644

18. Ordonez MP. Defective mitophagy in human Niemann-Pick Type $\mathrm{C} 1$ neurons is due to abnormal autophagy activation. Autophagy 2012; 8: 1157-1158.

19. Kim J, Cheon H, Jeong YT, Quan W, Kim KH, Cho JM et al. Amyloidogenic peptide oligomer accumulation in autophagy-deficient beta cells induces diabetes. J Clin Invest 2014; 124 3311-3324.

20. Kaushik S, Massey AC, Mizushima N, Cuervo AM. Constitutive activation of chaperone-mediated autophagy in cells with impaired macroautophagy. Mol Biol Cell 2008; 19: 2179-2192.

21. Zhang C, Cuervo AM. Restoration of chaperone-mediated autophagy in aging liver improves cellular maintenance and hepatic function. Nat Med 2008; 14: 959-965.

22. Rodriguez-Muela N, Koga H, Garcia-Ledo L, de la Villa P, de la Rosa EJ, Cuervo AM et al. Balance between autophagic pathways preserves retinal homeostasis. Aging Cell 2013; 12: 478-488.

23. Hartong DT, Berson EL, Dryja TP. Retinitis pigmentosa. Lancet 2006; 368: 1795-1809.

24. Fan J, Rohrer B, Frederick JM, Baehr W, Crouch RK. Rpe65-/-and Lrat - / - mice: comparable models of leber congenital amaurosis. Invest Ophthalmol Vis Sci 2008; 49: 2384-2389.

25. Lin J, LaVail M. Misfolded proteins and retinal dystrophies In: Anderson RE, Hollyfield JG LaVail MM (eds) Retinal Degenerative Diseases vol. 664. Springer: New York, 2010 pp 115-121.

26. Kunte MM, Choudhury S, Manheim JF, Shinde VM, Miura M, Chiodo VA et al. ER stress is involved in T17M rhodopsin-induced retinal degeneration. Invest Ophthal Vis Sci 2012; 53 : 3792-3800.

27. Travis GH, Golczak M, Moise AR, PalczewskiK. Diseases caused by defects in the visual cycle: retinoids as potential therapeutic agents. Annu Rev Pharmacol Toxicol 2007; 47: 469-512.

28. Bennett J. Gene therapy for color blindness. N Engl J Med 2009; 361: 2483-2484.
29. Sancho-Pelluz J, Arango-Gonzalez B, Kustermann S, Romero F, Veen T, Zrenner E et al. Photoreceptor Cell Death Mechanisms in Inherited Retinal Degeneration. Mol Neurobiol 2008; 38: 253-269.

30. Punzo $\mathrm{C}$, Kornacker $\mathrm{K}$, Cepko $\mathrm{CL}$. Stimulation of the insulin/mTOR pathway delays cone death in a mouse model of retinitis pigmentosa. Nat Neurosci 2009; 12: 44-52.

31. Kunchithapautham K, Coughlin B, Lemasters JJ, Rohrer B. Differential effects of rapamycin on rods and cones during light-induced stress in albino mice. Invest Ophthalmol Vis Sci 2011; 52: 2967-2975.

32. Murakami Y, Matsumoto H, Roh M, Suzuki J, Hisatomi T, Ikeda Y et al. Receptor interacting protein kinase mediates necrotic cone but not rod cell death in a mouse model of inherited degeneration. Proc Nat Acad Sci USA 2012; 109: 14598-14603.

33. Chen Y, Sawada O, Kohno H, Le YZ, Subauste C, Maeda T et al. Autophagy Protects the Retina from Light-induced Degeneration. J Biol Chem 2013; 288: 7506-7518.

34. Kim JY, Zhao H, Martinez J, Doggett TA, Kolesnikov AV, Tang PH et al. Noncanonical autophagy promotes the visual cycle. Cell 2013; 154: 365-376.

35. Kuma A, Hatano M, Matsui M, Yamamoto A, Nakaya H, Yoshimori T et al. The role of autophagy during the early neonatal starvation period. Nature 2004; 432: 1032-1036.

36. Komatsu M, Waguri S, Ueno T, Iwata J, Murata S, Tanida I et al. Impairment of starvationinduced and constitutive autophagy in Atg7-deficient mice. J Cell Biol 2005; 169: 425-434.

37. Klionsky DJ, Abdalla FC, Abeliovich H, Abraham RT, Acevedo-Arozena A, Adeli K et al. Guidelines for the use and interpretation of assays for monitoring autophagy. Autophagy 2012; 8: 445-544.

38. Mizushima N, Yoshimori T, Levine B. Methods in mammalian autophagy research. Cell 2010; 140: 313-326

39. Midorikawa R, Yamamoto-Hino M, Awano W, Hinohara Y, Suzuki E, Ueda R et at. Autophagy-dependent rhodopsin degradation prevents retinal degeneration in Drosophila. J Neurosci 2010; 30: 10703-10719.

40. Reme CE, Wolfrum U, Imsand C, Hafezi F, Williams TP. Photoreceptor autophagy: effects of light history on number and opsin content of degradative vacuoles. Invest Ophthalmol Vis Sci 1999; 40: 2398-2404.

41. Wenzel A, Reme CE, Williams TP, Hafezi F, Grimm C. The Rpe65 Leu450Met variation increases retinal resistance against light-induced degeneration by slowing rhodopsin regeneration. J Neurosci 2001; 21: 53-58.

42. Organisciak DT, Vaughan DK. Retinal light damage: mechanisms and protection. Prog Ret Eye Res 2010; 29: 113-134

43. Rosenzweig DH, Nair KS, Wei J, Wang Q, Garwin G, Saari JC et al. Subunit dissociation and diffusion determine the subcellular localization of rod and cone transducins. J Neurosci2007; 27: 5484-5494.

44. Lobanova ES, Herrmann R, Finkelstein S, Reidel B, Skiba NP, Deng WT et al. Mechanistic basis for the failure of cone transducin to translocate: why cones are never blinded by light. $J$ Neurosci 2010; 30: 6815-6824.

45. Zhang H, Huang W, Zhu X, Craft CM, Baehr W, Chen CK. Light-dependent redistribution of visual arrestins and transducin subunits in mice with defective phototransduction. Mol Vis 2003; 9: 231-237.

46. Kong L, Li F, Soleman CE, Li S, Elias RV, Zhou X et al. Bright cyclic light accelerates photoreceptor cell degeneration in tubby mice. Neurobiol Dis 2006; 21: 468-477.

47. Lobanova ES, Finkelstein S, Herrmann R, Chen YM, Kessler C, Michaud NA et al. Transducin gamma-subunit sets expression levels of alpha- and beta-subunits and is crucial for rod viability. J Neurosci 2008; 28: 3510-3520.

48. Organisciak DT, Xie A, Wang HM, Jiang YL, Darrow RM, Donoso LA. Adaptive changes in visual cell transduction protein levels: effect of light. Exp Eye Res 1991; 53: 773-779.

49. Mao W, Miyagishima KJ, Yao Y, Soreghan B, Sampath AP, Chen J. Functional comparison of rod and cone Galpha(t) on the regulation of light sensitivity. J Biol Chem 2013; 288: 5257-5267.

50. Tang PH, Buhusi MC, Ma JX, Crouch RK. RPE65 is present in human green/red cones and promotes photopigment regeneration in an in vitro cone cell model. J Neurosci 2011; 31 18618-18626.

51. Zhang T, Zhang N, Baehr W, Fu Y. Cone opsin determines the time course of cone photoreceptor degeneration in Leber congenital amaurosis. Proc Natl Acad Sci U S A 2011; 108: 8879-8884.

52. Le YZ, Zheng L, Zheng W, Ash JD, Agbaga MP, Zhu M et al. Mouse opsin promoter-directed Cre recombinase expression in transgenic mice. Mol Vis 2006; 12: 389-398.

53. Li S, Chen D, Sauve Y, McCandless J, Chen YJ, Chen CK. Rhodopsin-iCre transgenic mouse line for Cre-mediated rod-specific gene targeting. Genesis 2005; 41: 73-80.

54. Hara T, Nakamura K, Matsui M, Yamamoto A, Nakahara Y, Suzuki-Migishima R et al. Suppression of basal autophagy in neural cells causes neurodegenerative disease in mice. Nature 2006; 441: 885-889.

55. Mattapallil MJ, Wawrousek EF, Chan CC, Zhao H, Roychoudhury J, Ferguson TA et al. The Rd8 mutation of the Crb1 gene is present in vendor lines of C57BL/6 N mice and embryonic stem cells, and confounds ocular induced mutant phenotypes. Invest Ophthal Vis Sci 2012; 53: 2921-2927 